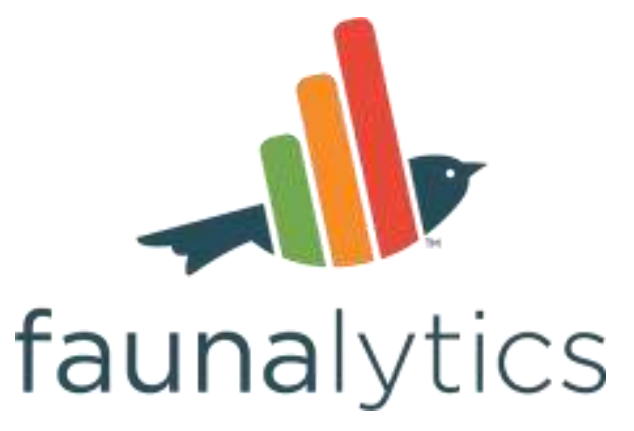

\title{
Messages to Overcome Naturalness Concerns in Clean Meat Acceptance: Primary Findings
}

\author{
July 2018
}

Authors: Jo Anderson \& Chris Bryant

Research team: Jo Anderson (Faunalytics), Chris Bryant (University of Bath), Kathryn Asher (Animal Charity Evaluators; formerly Faunalytics), Che Green (Faunalytics), Kris Gasteratos (Cellular Agriculture Society), Bruce Friedrich (The Good Food Institute), Jeff Rotman (Deakin University), Jamie Macfarlane (The Good Food Institute).

Funding: We gratefully acknowledge Animal Charity Evaluators and the Animal Advocacy Research Fund for their assistance in funding this project. 


\section{Introduction}

Studies of clean meat (also called cultured meat, in vitro meat, etc.) to date have found that consumers' willingness to eat it is uncertain (Pew Research, 2014; Slade, 2018; Surveygoo, 2018; The Grocer, 2017; Wilks \& Phillips, 2017; YouGov, 2013).

One of consumers' primary concerns about clean meat is its alleged unnaturalness. This is a theme that has been seen in many qualitative studies (Laestadius, 2015; Verbeke, Marcu, et al., 2015) and cited as one of the most common reasons for rejecting clean meat in surveys (The Grocer, 2017). Indeed, Siegrist and Sütterlin (2017) have demonstrated that the perceived unnaturalness of clean meat explains a great deal of consumers' safety concerns. Further, Siegrist, Sütterlin, and Hartmann (2018) show that this perception evokes disgust and likely causes rejection of clean meat in practice.

Similar consumer concerns likely contributed to policies restricting the cultivation of genetically modified (GM) foods in Western Europe (Schurman, 2004). Thus, identifying effective strategies for addressing the appeal to nature may be crucial to the success of clean meat.

The goal of this study was to find ways of describing clean meat that could address naturalness concerns and increase acceptance of this new product. Participants read one of three messages intended to address those concerns or a control message similar to those currently in use. They then answered questions about their acceptance of clean meat: willingness to try it, beliefs about it, emotional reaction to it, willingness to pay for it, and more.

We looked at whether different messages produced more or less acceptance of clean meat, and at overall rates of acceptance in the study relative to previous studies. Successful aspects of these messages can be used by advocates, lobbyists, and others to promote clean meat. The ultimate goal is to reduce reliance on animal farming by encouraging as many people as possible to switch to clean meat once it becomes available.

(C) Faunalytics 2018

\section{Contents}

Key Findings (page 3)

Methodology (page 4)

Terminology

Sample \& Procedure

Results (page 6)

Did Participants Believe the Messages?

Perceived Unnaturalness of Clean Meat

Perceived Unnaturalness of Conventional Meat

Perceived Importance of Meat Naturalness

Willingness to Pay (WTP) for Clean Meat

Behavioral Intentions

Beliefs about Clean Meat

Attitude

Affect

Overall Pattern of Results: Supplementary Analysis

Conclusions (page 16)

Experimental Messages

Implications

Limitations

Future Directions

References (page 19)

Appendix A: Messages and Measures (page 21)

Appendix B: Analysis Details (page 25)

Appendix C: Pairwise Comparisons (page 26) 


\section{Key Findings}

This report describes all analyses in detail in the Results section. Below we offer the most noteworthy findings.

1. Telling potential consumers about the unnatural side of conventionally-produced meat was effective: Potential consumers who read about the unnatural conditions in which farmed animals are raised were convinced that conventional meat is unnatural.

2. Describing conventionally-produced meat as unnatural produced the most acceptance of clean meat: Potential consumers who read this message were willing to pay more for clean meat than those who didn't. People who read this message also tended to be the most positive about clean meat in a variety of other ways: in their attitudes, feelings, and beliefs.

3. Trying to directly reduce naturalness concerns was ineffective: The other two messages tested in this study-which described the natural side of clean meat and attacked the idea that naturalness is important, respectively-were not convincing to participants. Given that these messages were developed by subject matter experts with multiple rounds of feedback, these arguments may be difficult or impossible to use effectively.

4. This study's messages produced more acceptance of clean meat than has been observed in many previous studies: All participants read a short introductory description of clean meat, then saw one of four experimental messages. Both the description and the messages described clean meat in positive terms, indicating its aesthetic and nutritional parallels with conventional meat and its benefits for the environment, health, and animals. They also, of course, used the term "clean meat" rather than an alternative. All of these features produced rates of willingness to eat clean meat that were higher than those observed in most previous research.

Specifically, in this study, $66.4 \%$ of people were wiling to try clean meat, $\mathbf{4 5 . 9 \%}$ were willing to buy clean meat regularly, and $\mathbf{5 2 . 8 \%}$ were willing to eat clean meat as a replacement for conventional meat. In contrast, a similar study conducted by Wilks and Phillips (2017) that examined base rates of acceptance without positive messaging found a similar rate of willingness to try clean meat $(65.3 \%)$, but substantially lower rates of willingness to eat it regularly $(32.6 \%)$ and willingness to replace conventional meat (31.5\%). Other recent studies that did not employ positive messaging have found lower rates of willingness to eat clean meat as well (e.g., Pew Research, 2014; Surveygoo, 2018). Despite differences in methodology across these studies, this provides some evidence that positive, educational messaging like ours may be effective in raising consumers' confidence in clean meat.

Further research will be needed to determine which aspects of this messaging are effective, as this study did not directly compare them. This type of research would be similar to studies conducted by Verbeke, Sans and Van Loo (2015) and Bekker, Fischer, Tobi and Van Trijp (2017) in Belgium and the Netherlands, respectively. In those studies, reading positive information about clean meat made participants more willing to try it and improved their attitudes toward it. 


\section{Methodology}

\section{Terminology}

Throughout the present study, we used the term 'clean meat,' though it is also sometimes called 'cultured meat' or 'in vitro meat.' We made this decision because several studies have shown that consumer acceptance is likely to be highest when using this name (Animal Charity Evaluators, 2017; The Good Food Institute, 2017) and subsequently, many organizations manufacturing clean meat will likely use this term. Therefore, a study using this nomenclature is likely to have the highest external validity.

At the same time, this choice of terminology represents a more conservative approach: To the extent that the name 'clean meat' reduces feelings of disgust compared to other names associated with the product, its effectiveness may overlap with the experimental conditions, which are also intended to reduce disgust. Thus, using this name reduced the chance of detecting a difference in acceptance between the control and experimental conditions.

\section{Sample \& Procedure}

Data were collected in January/February 2018. A census-balanced, representative sample of U.S. adults was recruited through the research firm Ipsos. Each person received Ipsos credit worth approximately $\$ 2$ for their participation. The final sample of $1,185^{1}$ people exceeded the 1,100 that our power analysis deemed necessary (details
Table 1. Demographic Characteristics of Sample

\begin{tabular}{lr}
\hline Full sample $(\boldsymbol{n})$ & $\mathbf{1 , 1 8 5}$ \\
\hline Female (\%) & 52.9 \\
\hline Age (Average) & 47.3 \\
\hline Race/Ethnicity (\%) & \\
White, non-Hispanic & 64.8 \\
Hispanic or Latino/Latina & 13.8 \\
Black or African American & 12.2 \\
Other races/More than one race & 9.2 \\
& \\
Region (\%) & 19.8 \\
Northeast & 20.6 \\
Midwest & 37.3 \\
South & 22.3 \\
West &
\end{tabular}

\section{Education (\%)}

Less than high school graduate $\quad 1.6$

High school graduate $\quad 35.7$

Some college, no degree $\quad 27.3$

Associate degree $\quad 5.6$

Bachelor's degree $\quad 16.7$

Master's degree $\quad 9.1$

Professional or doctorate degree $\quad 4.0$

Income (\%)

Less than $\$ 20,000$

$\$ 20,000$ to $\$ 39,999$

$\$ 40,000$ to $\$ 59,999$

$\$ 60,000$ to $\$ 79,999$

$\$ 80,000$ to $\$ 99,999$

$\$ 100,000$ or more $\quad 27.3$

Diet $^{\star}(\%)$

Omnivore $\quad 91.8$

Red meat avoider $\quad 3.5$

Pescetarian $\quad 2.5$

Vegetarian $\quad 1.4$

$\begin{array}{ll}\text { Vegan } & 0.8\end{array}$

* Categories were extrapolated from a basic

consumption question: "Which of the following do you

eat at least occasionally?"

\footnotetext{
${ }^{1}$ A surprisingly high proportion of survey respondents were automatically ejected from the study for failing one of two basic attention checks: Of 1,648 people who started the survey, $463(28 \%)$ were removed. Although this ensures that those who completed the study were paying attention, it may introduce a degree of selection bias and could be indicative of low panel quality.
} 
are available in the research design document).

Demographic characteristics of the sample are shown in Table 1.

We used an experimental survey design to compare the efficacy of four different messages addressing the naturalness concern. The design and experimental procedure for this study were pre-registered with the Open Science Framework.

The study procedure was as follows: Participants were block randomized to one of four conditions based on gender and diet (two characteristics found to predict acceptance of clean meat in previous studies). ${ }^{2}$ All participants answered questions about their familiarity with clean meat and read a brief passage describing it, to ensure that everyone's familiarity was equivalent before they received the experimental message.

The descriptive passage said: "Clean meat (also called cultured meat or in-vitro meat) is real meat which is grown from animal cells without the need to raise animals. It should not be confused with meat substitutes such as soy, since it is real animal meat: it has the same taste, texture, and the same or better nutritional content as conventionally-produced meat." ${ }^{3}$

The questions about participants' familiarity with clean meat are shown in Table 2. One preceded the descriptive passage, and one followed it, as indicated.

Table 2. Self-Rated Familiarity with Clean Meat

\begin{tabular}{llr}
\hline Question & Responses & Percentage (\%) \\
\hline $\begin{array}{l}\text { Have you heard the term "clean meat" before? (It has } \\
\text { sometimes been referred to as "cultured meat" or "in-vitro }\end{array}$ & No & 25.1 \\
meat" as well)? & Unsure & 59.7 \\
[asked before descriptive passage was provided] & & 15.3 \\
Prior to this study, to what extent were you familiar with & Not at all familiar & \\
clean meat (including under another name, such as & A little bit familiar & 64.1 \\
cultured meat or in-vitro meat)? & Moderately familiar & 21.3 \\
[asked after descriptive passage was provided] & Familiar & 7.8 \\
& Very familiar & 4.4 \\
\hline
\end{tabular}

Participants then read one of four experimental messages. Each one began with the same introductory paragraph, followed by one of the four messages about naturalness: an argument that clean meat is natural, an argument that conventionally-produced meat is unnatural so clean meat is preferable, an argument challenging the appeal to nature, or a control message about the

\footnotetext{
2 No significant differences between experimental groups emerged on relevant demographic factors including age, gender, race, state, education, income, and familiarity with clean meat. This demonstrates that random assignment was successful.

${ }^{3}$ It is worth noting that the provision about taste, texture, and nutritional value has not been included in most previous research. It was included in this study to accurately reflect the conditions under which clean meat will come to market.
} 
benefits of clean meat for health, the environment, and animals. The messages are shown in Table A-1 in Appendix A.

Following the experimental message, participants answered questions to examine whether the messages had the intended effect (called "manipulation checks"). They then responded to questions about their behavioral intentions, attitudes, beliefs, affective (emotional) reactions, and willingness to pay (WTP) for clean meat (chicken nuggets, beef burgers, and fish sticks). These measures are summarized in Tables A-2 and A-3 in Appendix A. For the full survey in context, with details of randomization, see the research design document.

\section{Results}

Details of the statistical analyses are provided in Appendix B. For the full set of pairwise comparisons for self-report variables, see Appendix C.

This section of the report shows the average response to each message for each outcome variable. When the average for one of the experimental messages was significantly different from in the control condition, it is presented in bold.

\section{Did Participants Believe the Experimental Messages?}

Analyses of the manipulation checks revealed that the experimental messages produced mixed results, as described below. Table 6 shows the average response to each message.

Table 6. Manipulation Check Averages

\begin{tabular}{lccc|c}
\hline & $\begin{array}{c}\text { Clean meat is } \\
\text { natural }\end{array}$ & $\begin{array}{c}\text { Conventional } \\
\text { meat is } \\
\text { unnatural }\end{array}$ & $\begin{array}{c}\text { Challenging } \\
\text { appeal to } \\
\text { nature }\end{array}$ & Control \\
\hline $\begin{array}{l}\text { Perceived unnaturalness of } \\
\text { clean meat }\end{array}$ & 3.0 & 2.9 & 3.0 & 3.0 \\
$\begin{array}{l}\text { Perceived unnaturalness of } \\
\text { conventional meat }\end{array}$ & 2.6 & 2.8 & 2.5 & 2.5 \\
$\begin{array}{l}\text { Perceived importance of } \\
\text { naturalness }\end{array}$ & 3.9 & 3.8 & 3.7 & 3.8 \\
\hline
\end{tabular}

Response options ranged from 1 (strongly disagree) to 5 (strongly agree). Bold = significantly different from control.

\section{Perceived unnaturalness of clean meat}

If the messaging was persuasive, participants in the 'clean meat is natural' condition would have been less likely to perceive clean meat as unnatural than in the control condition, but there was no significant difference, as shown in Table 6 . This finding strongly suggests that our attempt to convince participants of the naturalness of clean meat was unsuccessful. 
Given that no significant condition differences emerged, we considered the top-line results, which indicated that concerns about the naturalness of clean meat were held by only a minority of participants. Across all conditions, $\mathbf{3 4 . 1 \%}$ agreed or strongly agreed with the statement that "clean meat is unnatural," while $\mathbf{3 4 . 2 \%}$ disagreed or strongly disagreed, and $\mathbf{3 1 . 6 \%}$ neither agreed nor disagreed.

\section{Perceived unnaturalness of conventional meat}

As shown in Table 6, the manipulation check supported the success of the persuasive messaging arguing that conventional meat is unnatural: Participants in that condition were significantly more likely to perceive conventional meat as unnatural than in the control condition.

Considering the results across all participants and conditions, $20.0 \%$ agreed or strongly agreed with the statement that "conventionally-produced meat is unnatural," while $\mathbf{4 8 . 9 \%}$ disagreed or strongly disagreed, and $\mathbf{3 1 . 1 \%}$ neither agreed nor disagreed. However, it is important to note the significant variation by condition, as shown in Table 6 .

\section{Perceived importance of meat naturalness}

If the messaging was persuasive, participants in the 'challenging the appeal to nature' condition would have been less likely to perceive naturalness as important than in the control condition, but the difference between these two means was not significant, as shown in Table 6. This finding suggests that our attempt to convince participants that naturalness in meat is unimportant was relatively unsuccessful.

Considering the results across all participants and conditions, $65.8 \%$ agreed or strongly agreed with the statement that "it is important for meat to be natural," while only $8.6 \%$ disagreed or strongly disagreed, and $\mathbf{2 5 . 7 \%}$ neither agreed nor disagreed. However, there was again significant variation by condition that must be noted, as can be seen in Appendix C. Differences between the control and experimental conditions were not significant so they are not described here.

\section{Willingness to Pay (WTP) for Clean Meat}

Figure 1 shows participants' WTP for clean meat. It shows the results separately for each of the four messages tested and three hypothetical clean meat products. As the graph indicates, all three products showed similar results. Although we analyzed them separately, that overall pattern should be considered. Using the significance conventions laid out in Appendix B, several findings are worth noting.

First, relative to the control condition, people in the 'conventional meat is unnatural' condition were willing to pay significantly more for fish $\left(p=.03\right.$; indicated with $\left.{ }^{*}\right)$ and marginally more for chicken 
$(p=.08$; indicated with $\dagger)$. The findings for beef, while non-significant $(p=.13)$, were in the same direction. ${ }^{4,5}$

\section{Figure 1: Willingness to pay for clean meat relative to conventional meat}

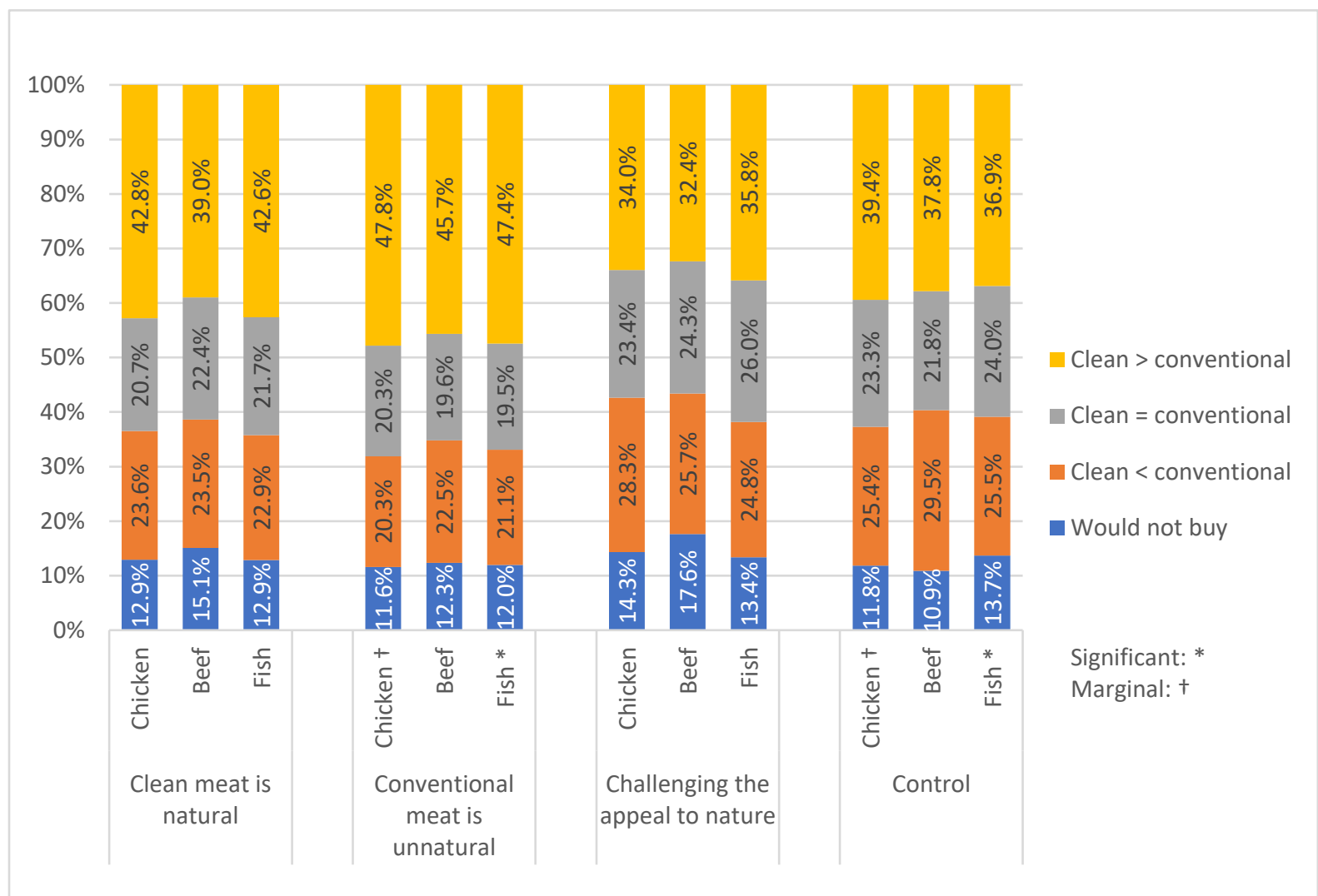

We know that advocates and manufacturers of clean meat would like a better idea of the actual amounts people will be willing to pay. Because of this keen interest and the lack of available data, we will provide rough estimates in a follow-up blog post. Although we hope this analysis will be useful, it is also quite speculative, with several important limitations to bear in mind.

\footnotetext{
${ }^{4}$ Of less relevance to advocates, people in the 'conventional meat is unnatural' condition were willing to pay significantly more than in the 'challenging the appeal' condition for chicken $(p=.002)$ and beef $(p=.002)$, and marginally more for fish ( $p=.03$; marginal at the Bonferroni-corrected post-hoc alpha level of .0167).

5 To ensure that these results are not reliant on the particular analysis we chose, we also conducted non-parametric tests comparing the median WTP for each product in the experimental conditions against the control condition. The analyses comparing conventional meat is unnatural to control were marginally significant for chicken, beef, and fish ( $p$ s $<.06$ ), which supports the results of our main WTP analysis. Neither of the other two experimental conditions differed, significantly or marginally, from the control condition.
} 


\section{Behavioral Intentions}

The average self-reported willingness to try clean meat and other behavioral intentions items mirrored the pattern of the WTP findings above, but none of the differences were significant. The average responses for each message are shown in Table 7. For full details, see Appendix C.

Table 7. Average Behavioral Intentions

\begin{tabular}{lccc|c}
\hline & $\begin{array}{c}\text { Clean meat is } \\
\text { natural }\end{array}$ & $\begin{array}{c}\text { Conventional } \\
\text { meat is } \\
\text { unnatural }\end{array}$ & $\begin{array}{c}\text { Challenging } \\
\text { appeal to } \\
\text { nature }\end{array}$ & Control \\
\hline $\begin{array}{l}\text { Willingness to try clean } \\
\text { meat }\end{array}$ & 3.8 & 4.0 & 3.8 & 3.9 \\
$\begin{array}{l}\text { Willingness to buy clean } \\
\text { meat regularly }\end{array}$ & 3.5 & 3.6 & 3.4 & 3.5 \\
$\begin{array}{l}\text { Willingness to eat clean } \\
\text { meat as a replacement for } \\
\text { conventional meat }\end{array}$ & 3.5 & 3.7 & 3.5 & 3.6 \\
$\begin{array}{l}\text { Willingness to eat clean } \\
\text { meat compared to plant- } \\
\text { based substitutes (current } \\
\text { consumers, } n=381 \text { ) }\end{array}$ & 3.7 & 3.8 & 3.5 & 3.7 \\
$\begin{array}{l}\text { Willingness to eat clean } \\
\text { meat compared to plant- } \\
\text { based substitutes (non- } \\
\text { consumers, } n=804)\end{array}$ & 3.8 & & & \\
\hline
\end{tabular}

Response options ranged from 1 (definitely no) to 5 (definitely yes).

Table 8 shows a breakdown of the responses for each of the behavioral intentions items. Overall rates of acceptance were fairly high. 
Table 8. Behavioral Intentions Responses

\begin{tabular}{|c|c|c|c|}
\hline \multicolumn{2}{|l|}{ Question | Sample } & Responses & Percentage (\%) \\
\hline \multicolumn{2}{|c|}{ Would you be willing to try clean meat? } & $\begin{array}{l}\text { Definitely yes } \\
\text { Probably yes } \\
\text { I am unsure } \\
\text { Probably no } \\
\text { Definitely no }\end{array}$ & $\begin{array}{r}33.8 \\
32.6 \\
21.6 \\
6.1 \\
6.0\end{array}$ \\
\hline \multicolumn{2}{|c|}{$\begin{array}{l}\text { Would you be willing to buy clean meat } \\
\text { regularly? }\end{array}$} & $\begin{array}{l}\text { Definitely yes } \\
\text { Probably yes } \\
\text { I am unsure } \\
\text { Probably no } \\
\text { Definitely no }\end{array}$ & $\begin{array}{r}17.5 \\
28.4 \\
37.7 \\
8.9 \\
7.5\end{array}$ \\
\hline \multicolumn{2}{|c|}{$\begin{array}{l}\text { Would you be willing to eat clean meat as a } \\
\text { replacement for conventionally-produced } \\
\text { meat? }\end{array}$} & $\begin{array}{l}\text { Definitely yes } \\
\text { Probably yes } \\
\text { I am unsure } \\
\text { Probably no } \\
\text { Definitely no }\end{array}$ & $\begin{array}{r}17.8 \\
35.0 \\
30.4 \\
9.4 \\
7.5\end{array}$ \\
\hline $\begin{array}{l}\text { How willing would you be to } \\
\text { eat clean meat compared to } \\
\text { plant-based substitutes (e.g., } \\
\text { soy)? }\end{array}$ & $\begin{array}{l}\text { Current eaters of } \\
\text { plant-based } \\
\text { substitutes } \\
(n=381)\end{array}$ & $\begin{array}{l}\text { Much more } \\
\text { Somewhat more } \\
\text { Neither more nor less } \\
\text { Somewhat less } \\
\text { Much less }\end{array}$ & $\begin{array}{r}24.4 \\
32.3 \\
28.9 \\
8.4 \\
6.0\end{array}$ \\
\hline $\begin{array}{l}\text { How willing would you be to } \\
\text { eat clean meat compared to } \\
\text { plant-based substitutes (e.g., } \\
\text { soy)? }\end{array}$ & $\begin{array}{l}\text { Current non- } \\
\text { eaters of plant- } \\
\text { based substitutes } \\
(n=804)\end{array}$ & $\begin{array}{l}\text { Much more } \\
\text { Somewhat more } \\
\text { Neither more nor less } \\
\text { Somewhat less } \\
\text { Much less }\end{array}$ & $\begin{array}{r}28.2 \\
34.5 \\
27.1 \\
4.4 \\
5.8\end{array}$ \\
\hline
\end{tabular}

${ }^{1}$ For this question, participants were also given the option of selecting 'Not applicable (I do not eat conventionallyproduced meat).' It was selected by 19 participants.

Specifically, in this study, $66.4 \%$ of people were (probably or definitely) wiling to try clean meat, $45.9 \%$ were willing to buy clean meat regularly, and $52.8 \%$ were willing to eat clean meat as a replacement for conventional meat. In contrast, a study conducted by Wilks and Phillips (2017) that examined base rates of acceptance without positive messaging found a similar rate of willingness to try in-vitro meat ${ }^{6}(65.3 \%)$, but substantially lower rates of willingness to eat it regularly (32.6\%) and willingness to replace conventional meat (31.5\%).

Other studies that did not use positive messaging have also found low rates of willingness to eat clean meat. A few years ago, Pew Research (2014) estimated that $20 \%$ of U.S. adults would eat "meat that was grown in a lab" and YouGov (2013) found that 19\% of UK adults would eat "artificial meat" (their terminology). More recently, the Grocer (2017) estimated that $16 \%$ of adults in the UK would buy clean meat (reported in Bryant \& Barnett, 2018), and Surveygoo (2018) reported that $40 \%$ of U.S. adults and $18 \%$ of UK adults would be willing to eat clean meat.

6 The term they used in the study. 


\section{Beliefs about Clean Meat}

None of the experimental messages produced significantly more positive beliefs than the control message, although the 'conventional meat is unnatural' message performed better than the 'challenging the appeal to nature' message in several cases, as shown in Appendix C.

The only significant difference from the control message was on the belief that clean meat would be environmentally friendly: Participants who read the 'challenging the appeal to nature' message were significantly less likely to believe this.

The average responses for each message are shown in Table 9.

Table 9. Average Beliefs about Clean Meat

\begin{tabular}{lccc|c}
\hline & $\begin{array}{c}\text { Clean meat } \\
\text { is natural }\end{array}$ & $\begin{array}{c}\text { Conventiona } \\
\text { I meat is } \\
\text { unnatural }\end{array}$ & $\begin{array}{c}\text { Challenging } \\
\text { appeal to } \\
\text { nature }\end{array}$ & Control \\
\hline Clean meat is likely to be healthy & 3.6 & 3.8 & 3.5 & 3.7 \\
$\begin{array}{l}\text { Clean meat is likely to be safe for } \\
\text { human consumption }\end{array}$ & 3.7 & 3.8 & 3.6 & 3.7 \\
$\begin{array}{l}\text { Clean meat is more environmentally- } \\
\text { friendly than conventionally- } \\
\text { produced meat }\end{array}$ & 4.0 & 4.1 & 3.9 & 4.1 \\
\hline $\begin{array}{l}\text { Clean meat is likely to look, taste, } \\
\text { smell, and feel the same as } \\
\text { conventionally-produced meat }\end{array}$ & 3.6 & 3.7 & 3.5 & 3.6 \\
\hline $\begin{array}{l}\text { Clean meat will have benefits for } \\
\text { society }\end{array}$ & 3.8 & 3.8 & 3.7 & 3.9 \\
\hline
\end{tabular}

Response options ranged from 1 (strongly disagree) to 5 (strongly agree). Bold = significantly different from control.

Table 10 shows a breakdown of the responses for each of the beliefs statements. Overall, beliefs about clean meat were generally positive. It is also worth noting the relatively high rates of "neither agree nor disagree" responses. This suggests that a substantial proportion of the population has largely unformed opinions about clean meat and may be persuadable with education. 
Table 10. Behavioral Intentions Responses

\begin{tabular}{llr}
\hline & Responses & Percentage (\%) \\
\hline Clean meat is likely to be healthy & Strongly disagree & 3.5 \\
& Disagree & 5.9 \\
& Neither agree nor disagree & 34.1 \\
& Agree & 39.2 \\
& Strongly agree & 17.3 \\
Clean meat is likely to be safe for human & Strongly disagree & 3.7 \\
consumption & Disagree & 5.1 \\
& Neither agree nor disagree & 30.4 \\
& Agree & 41.2 \\
Clean meat is more environmentally-friendly & Strongly agree & 19.7 \\
than conventionally-produced meat & Strongly disagree & 2.6 \\
& Disagree & 3.0 \\
& Neither agree nor disagree & 21.9 \\
Clean meat is likely to look, taste, smell, and & Agree & 40.8 \\
feel the same as conventionally-produced & Strongly disagree & 31.7 \\
meat & Disagree & 3.5 \\
& Neither agree nor disagree & 10.3 \\
& Agree & 30.0 \\
Clean meat will have benefits for society & Strongly agree & 41.5 \\
& Strongly disagree & 14.8 \\
\hline
\end{tabular}

\section{Attitude}

None of the experimental messages produced significantly more positive attitudes than the control message, although again, the 'conventional meat is unnatural' message performed better than the 'challenging the appeal to nature' message (see Appendix C).

The 'challenging the appeal to nature' message produced significantly worse attitudes than the control message. This finding recommends not using this type of argument.

The average responses for each message are shown in Table 11. 
Table 11. Average Attitudes toward Clean Meat

\begin{tabular}{lccc|c}
\hline & $\begin{array}{c}\text { Clean meat } \\
\text { is natural }\end{array}$ & $\begin{array}{c}\text { Conventiona } \\
\text { I meat is } \\
\text { unnatural }\end{array}$ & $\begin{array}{c}\text { Challenging } \\
\text { appeal to } \\
\text { nature }\end{array}$ & Control \\
\hline Attitude toward clean meat & 4.8 & 5.1 & 4.7 & 5.0 \\
\hline
\end{tabular}

Response options ranged from 1 (extremely bad/unpleasant) to 7 (extremely good/pleasant). Bold = significantly different from control.

Table 12 shows a breakdown of the responses for each of the two attitude items. Overall, attitudes toward clean meat were generally positive.

Table 12. Attitude Responses

\begin{tabular}{llr}
\hline & Responses & Percentage (\%) \\
\hline For me to eat clean meat would be... & Extremely bad & 3.4 \\
& Bad & 2.3 \\
& Somewhat bad & 3.8 \\
& Neither good nor bad & 26.8 \\
& Somewhat good & 18.1 \\
& Good & 28.8 \\
& Extremely good & 17.0 \\
\hline For me to eat clean meat would be $\ldots$ & Extremely unpleasant & 4.6 \\
& Unpleasant & 4.0 \\
& Somewhat unpleasant & 7.3 \\
& Neither unpleasant nor pleasant & 36.1 \\
& Somewhat pleasant & 17.3 \\
& Pleasant & 20.9 \\
& Extremely pleasant & 9.7 \\
\hline
\end{tabular}

\section{Affect}

'Affect' refers to an in-the-moment emotional state. No significant differences in the affect composite (i.e., the average of the six affect items) emerged between conditions. 
The average responses for each message are shown in Table 13.

Table 13. Average Affective Reaction to Clean Meat

\begin{tabular}{lccc|c}
\hline & $\begin{array}{c}\text { Clean meat } \\
\text { is natural }\end{array}$ & $\begin{array}{c}\text { Conventiona } \\
\text { I meat is } \\
\text { unnatural }\end{array}$ & $\begin{array}{c}\text { Challenging } \\
\text { appeal to } \\
\text { nature }\end{array}$ & Control \\
\hline Positive affect & 3.4 & 3.6 & 3.4 & 3.5 \\
\hline
\end{tabular}

The affect composite included three positively-worded items and three negatively-worded items. The items were coded so that higher scores represent more positive affect. Response options ranged from 1 (not at all) to 5 (extremely).

Table 14 shows a breakdown of the responses for each of the affect items. Overall, people felt fairly neutral about clean meat, showing no strong positive or negative bias.

One particular affect item-disgusted-is worth additional consideration, given its connection to the alleged unnaturalness of clean meat (Siegrist et al., 2018). Just 5.2\% of participants said they felt extremely disgusted about the idea of eating clean meat, whereas $57.6 \%$ said they felt not at all disgusted. Disgust was low overall $(M=1.8)$ and did not differ significantly by condition. ${ }^{7}$

${ }^{7}$ All post hoc corrected $p s>.22$. 
Table 14. Affect Items

\begin{tabular}{|c|c|c|}
\hline Measure & Responses & Percentage (\%) \\
\hline Disgusted $^{*}$ & $\begin{array}{l}\text { Extremely } \\
\text { Quite a bit } \\
\text { Moderately } \\
\text { A little } \\
\text { Not at all }\end{array}$ & $\begin{array}{r}5.2 \\
5.1 \\
10.1 \\
21.9 \\
57.6\end{array}$ \\
\hline Excited & $\begin{array}{l}\text { Extremely } \\
\text { Quite a bit } \\
\text { Moderately } \\
\text { A little } \\
\text { Not at all }\end{array}$ & $\begin{array}{l}12.0 \\
15.9 \\
21.2 \\
21.4 \\
29.6\end{array}$ \\
\hline Anxious* & $\begin{array}{l}\text { Extremely } \\
\text { Quite a bit } \\
\text { Moderately } \\
\text { A little } \\
\text { Not at all }\end{array}$ & $\begin{array}{r}5.2 \\
12.3 \\
19.1 \\
30.4 \\
33.0\end{array}$ \\
\hline Comfortable & $\begin{array}{l}\text { Extremely } \\
\text { Quite a bit } \\
\text { Moderately } \\
\text { A little } \\
\text { Not at all }\end{array}$ & $\begin{array}{l}12.5 \\
17.5 \\
27.3 \\
22.1 \\
20.7\end{array}$ \\
\hline Ethical & $\begin{array}{l}\text { Extremely } \\
\text { Quite a bit } \\
\text { Moderately } \\
\text { A little } \\
\text { Not at all }\end{array}$ & $\begin{array}{l}17.0 \\
22.4 \\
26.6 \\
16.9 \\
17.0\end{array}$ \\
\hline Immoral* $^{*}$ & $\begin{array}{l}\text { Extremely } \\
\text { Quite a bit } \\
\text { Moderately } \\
\text { A little } \\
\text { Not at all }\end{array}$ & $\begin{array}{r}4.0 \\
4.7 \\
9.9 \\
16.2 \\
65.2\end{array}$ \\
\hline
\end{tabular}

${ }^{\star}$ This item was reverse-scored for creating the affect composite.

\section{Overall Pattern of Results: Supplementary Analysis}

We created a composite variable representing overall clean meat acceptance for a supplementary analysis. ${ }^{8}$ The goal of this analysis was to aid interpretation by providing an overall picture of the pattern of results for the self-report measures (essentially averaging all the results).

${ }^{8}$ Compositing is supported by a very high reliability score, $\alpha=.95$, and most correlations between predictors being 0.5 or greater (Song, Lin, Ward, \& Fine, 2013). This composite was created by averaging standardized versions of all selfreport outcome variables in the study: the attitude composite, the affect composite, the five cognitive beliefs items, and the four behavioral intentions items. The predictor variables used in this analysis were also standardized. 
When all self-report measures are considered together, only one difference between averages was significant: Participants in the 'conventional meat is unnatural' condition were more accepting of clean meat than those in the 'challenging the appeal' condition $(p=.008) .{ }^{9}$ Thus, it is clear that of these two messages, arguing for the unnaturalness of conventional meat is the better choice.

\section{Conclusions}

This study's messages produced more acceptance of clean meat than has been observed in many previous studies. Specifically, in this study, $66.4 \%$ of people were wiling to try clean meat, $\mathbf{4 5 . 9 \%}$ were willing to buy clean meat regularly, and $\mathbf{5 2 . 8 \%}$ were willing to eat clean meat as a replacement for conventional meat.

In contrast, a similar study conducted by Wilks and Phillips (2017) that examined base rates of acceptance without positive messaging found a similar rate of willingness to try clean meat $(65.3 \%)$, but substantially lower rates of willingness to eat it regularly (32.6\%) and willingness to replace conventional meat (31.5\%). Other recent studies that did not employ positive messaging have found lower rates of willingness to eat clean meat as well (e.g., Pew Research, 2014; Surveygoo, 2018). Despite differences in methodology across these studies, this provides some evidence that positive, educational messaging like ours may be effective in raising consumers' confidence in clean meat.

Further research will be needed to determine which aspects of this messaging are effective, as this study did not directly compare them. This type of research would be similar to studies conducted by Verbeke, Sans and Van Loo (2015) and Bekker, Fischer, Tobi and Van Trijp (2017) in Belgium and the Netherlands, respectively. In those studies, reading positive information about clean meat made participants more willing to try it and improved their attitudes toward it.

\section{Experimental Messages}

Although the experimental messages were developed with several rounds of consultation from researchers and industry insiders and were pretested for how well they conveyed the intended meaning, our checks suggested that only one of the three was truly successful in convincing readers of that message. Participants accepted the argument that conventionally-produced meat is unnatural, but not that clean meat is natural nor that naturalness should not matter.

Most notably, the 'conventional meat is unnatural' message performed best when participants were asked how much they were willing to pay for clean meat. When they read about the unnaturalness of conventional meat, participants were willing to pay more for clean meat than for conventional meat.

On the self-report measures, the argument that conventional meat is unnatural did not significantly out-perform a control message, although it produced the most positive results of the four conditions on almost all outcomes (see Table 6). The only significant difference was between the

\footnotetext{
${ }^{9}$ Pairwise differences between means were examined using Tukey's HSD. All other ps > .12.
} 
'conventional meat is unnatural' and 'challenging the appeal to nature' conditions-the latter performing the worst.

In sum, the argument that conventional meat is unnatural influenced participants' willingness to pay for clean meat more than it did their stated intentions, beliefs, and feelings about it. The reason for this is logical: As the manipulation check showed, this argument influenced perceptions of conventional meat but not clean meat. The study's self-report measures did not assess the appeal of conventional meat directly or indirectly, but the WTP measure did, by pitting the two products against each other. However, to the extent that the WTP measure is more similar to real consumer behavior than self-reported scale ratings, this is a tentatively positive result for advocates. This is explored further below.

\section{Implications}

In a real-world context, consumers will not answer questions about their willingness to eat clean meat, they will be faced with a choice between it and the more familiar, conventionally-produced meat. These results suggest that, in that choice context, focusing on the unnatural aspects of conventional meat may be the most effective way of increasing interest in clean meat. In short, it appears to make consumers more aware of the positive contrast between them.

That being said, such an approach would represent a fairly aggressive stance towards conventional meat producers, which may not be an optimal strategy for advancing clean meat. Several conventional meat producers are already backing clean meat technology, so encouraging others to do so as well may be a better strategy than fighting them with legal challenges or marketing. This question warrants further consideration.

Given the care that was taken in developing the experimental messages, and the lack of other effects, we believe it is reasonable to interpret these results as an indication that arguing for clean meat's naturalness or the unimportance of naturalness are difficult strategies to use effectively.

\section{Limitations}

As with all research, this study was subject to several limitations. First, because only U.S. adults were studied, the findings may not be generalizable to other cultures or countries.

In addition, the proportion of would-be participants who were removed for failing attention checks was higher than we would like. Although their removal ensures data quality, it may introduce some selection bias. More generally, it may be indicative of low panel quality.

It is also worth noting several limitations of the WTP measure in particular. First, it is important to bear in mind that this measure directly followed positive messaging about clean meat, potentially producing higher values than would be observed in reality. In addition, because this measure is hypothetical, it is susceptible to the commonly-observed hypothetical bias, in which consumers tend to overestimate how much they are willing to pay for a product (e.g., Loomis, 2011). It is for this reason that we have provided only broad WTP categories above and focused on the comparison between conditions.

Participants' self-report responses may also be subject to bias. First, forecasting error is probable: Predicting one's own future attitudes and behaviors towards a product which is not yet available 
is difficult (Bryant \& Barnett, 2018). Unfortunately, there is little that can be done to avoid it, as clean meat is not yet available. Hypothetical and predictive questions are the only option, though we took care to frame them as realistically as possible.

Finally, participants may have been subject to social desirability bias-answering as they believe others would want them to-for questions about a product with such profound ethical and environmental implications (Grimm, 2010). That said, because even participants who read our control message were exposed to arguments about these implications, we believe that the potential impact of this bias is minimal.

\section{Future Directions}

We suggest that future research carefully consider whether trying to directly overcome perceptions of unnaturalness is the most effective option before pursuing it further-a few of this study's effects suggest there may even be potential for it to backfire. These results suggest that a focus on the unnaturalness of conventionally-produced meat is more likely to be effective, but as noted above, this is not without risk of alienating potential allies.

In addition, the effectiveness of the 'conventional meat is unnatural' message in this study was limited, with mixed results across different outcome measures. We recommend that, if this is to be considered as a strategy for advancing clean meat, further testing of similar and stronger messages should be carried out.

The overall high rates of clean meat acceptance observed in this study suggest another potential strategy: that providing potential consumers with positive educational messaging about the benefits and characteristics of clean meat may be a good way to reduce the emphasis on naturalness before it becomes the focus of the conversation. This study does not provide strong evidence about this possibility because we did not include a no-message control group, opting instead for current messaging. Previous research that has directly examined the impact of positive messaging has found that it can be effective (Verbeke et al., 2015; Bekker et al., 2017).

We recommend that future research do more to examine which aspects of educational messages are most effective in increasing acceptance rates: for instance, information about the taste, texture, and nutritional profile, or the health, environmental, or animal welfare benefits. This study included all of these to apparent good effect, but further experimental research will be needed to narrow down the key ingredients so that they can be emphasized. 


\section{References}

Animal Charity Evaluators. (2017). "Clean" Meat or "Cultured" Meat: A Randomized Trial Evaluating the Impact on Self-Reported Purchasing Preferences. Retrieved 13 June, 2017, from https://animalcharityevaluators.org/blog/clean-meat-or-cultured-meat-arandomized-trial-evaluating-the-impact-on-self-reported-purchasing-preferences/

Bekker, G. A., Fischer, A. R. H., Tobi, H., \& van Trijp, H. C. M. (2017). Explicit and implicit attitude toward an emerging food technology: The case of cultured meat. Appetite, 108, 245-254. https://doi.org/10.1016/i.appet.2016.10.002

Bryant, C. J., \& Barnett, J. C. (2018). Consumer acceptance of cultured meat: A systematic review. Meat Science, 143, 8-17. doi: https://doi.org/10.1016/j.meatsci.2018.04.008

Grimm, P. (2010). Social desirability bias. Wiley International Encyclopedia of Marketing. doi: 10.1002/9781444316568.wiem02057

Laestadius, L. (2015). Public Perceptions of the Ethics of In-vitro Meat: Determining an Appropriate Course of Action. Journal of Agricultural \& Environmental Ethics, 28, 9911009. doi: 10.1007/s10806-015-9573-8

Loomis, J. (2011). What's to know about hypothetical bias in stated preference valuation studies? Journal of Economic Surveys, 25, 363-370. https://doi.org/10.1111/j.14676419.2010.00675.x

Pew Research (2014). U.S. views of technology and the future: Science in the next 50 years.

Schurman, R. (2004). Fighting "Frankenfoods": Industry opportunity structures and the efficacy of the anti-biotech movement in Western Europe. Social Problems, 51, 243-268.

Siegrist, M., \& Sütterlin, B. (2017). Importance of perceived naturalness for acceptance of food additives and cultured meat. Appetite, 113, 320-326. doi: 10.1016/j.appet.2017.03.019

Siegrist, M., Sütterlin, B., \& Hartmann, C. (2018). Perceived naturalness and evoked disgust influence acceptance of cultured meat. Meat Science, 139, 213-219.

Slade, P. (2018). If you build it, will they eat it? Consumer preferences for plant-based and cultured meat burgers. Appetite, 125, 428-437.

Song, M., Lin, F., Ward, S. E., \& Fine, J. P. (2013). Composite variables: When and how. Nursing Research, 62, 45-49. https://doi.org/10.1097/NNR.0b013e3182741948

Surveygoo. (2018). Nearly one in three consumers willing to eat lab-grown meat, according to new research. Retrieved March 1, 2018, from https://www.datasmoothie.com/@surveygoo/nearly-one-in-three-consumers-willing-toeat-lab-g/

The Good Food Institute. (2017). Clean meat: The naming of tissue-engineered meat. Retrieved 13 June, 2017, from http://mfait.gfi.org/the-naming-of-clean-meat 
The Grocer. (2017). Meat the future... and how to market it. Retrieved February 21, 2017, from http://www.thegrocer.co.uk/buying-and-supplying/categories/meat/meat-the-future-andhow-to-market-it/546754.article

Verbeke, W., Marcu, A., Rutsaert, P., Gaspar, R., Seibt, B., Fletcher, D., \& Barnett, J. (2015). 'Would you eat cultured meat?': Consumers' reactions and attitude formation in Belgium, Portugal and the United Kingdom. Meat Science, 102, 49-58. doi: 10.1016/j.meatsci.2014.11.013

Verbeke, W., Sans, P., \& Van Loo, E. J. (2015). Challenges and prospects for consumer acceptance of cultured meat. Journal of Integrative Agriculture, 14, 285-294. doi: 10.1016/S2095-3119(14)60884-4

Wilks, M., \& Phillips, C. J. (2017). Attitudes to in vitro meat: A survey of potential consumers in the United States. PloS One, 12.

YouGov (2013). No British demand for fake meat. Retrieved August 13, 2017, from https://yougov.co.uk/news/2013/08/05/no-demand-fake-meat/ 


\section{Appendix A: Messages and Measures}

Table A-1. Experimental Messages ${ }^{10}$

\begin{tabular}{ll}
\hline Section/Condition & Message \\
\hline $\begin{array}{l}\text { Introductory passage } \\
\text { (shown to all }\end{array}$ & $\begin{array}{l}\text { Clean meat is real meat, grown from animal cells without the need to } \\
\text { raise and slaughter farm animals. It has significant benefits for the } \\
\text { participants) }\end{array}$ \\
$\begin{array}{l}\text { environment, animals, and human health. Products include chicken (as } \\
\text { shown), beef, and more! }\end{array}$
\end{tabular}

Clean meat is natural

\section{Conventional meat is unnatural}

\section{Challenging the appeal to nature}

Clean meat products are made using a natural process very similar to the way yogurt and beer are fermented. This is a method which has been used in food manufacturing for thousands of years. The development of clean meat resembles how muscles naturally grow within an animal very closely. In fact, this process of cell growth is present in all natural life.

Clean meat has many benefits for human health, animals, and the environment. But best of all, it's all-natural!

Production of conventional meat today is far from natural. Animals are fed antibiotics and hormones so that they grow much faster and larger than they would in nature. Unsanitary farming conditions increase the risk of contamination from feces, as well as viruses and bacteria. The meat also contains additives, artificial coloring, and preservatives, and is often treated with radiation.

Clean meat avoids all of those issues. It has many benefits for human health, animals, and the environment. But best of all, it's just meat!

You might think that clean meat is unnatural, but naturalness does not necessarily mean goodness. Indeed, most modern food (including rice, tomatoes, milk, and - yes - meat) has been manipulated by people to make it suit our needs, and it is tastier and more nutritious as a result. On the other hand, some plants (like many types of poisonous mushroom) are completely natural but can easily kill you.

Clean meat has many benefits for human health, animals, and the environment. It's a perfect example of humans improving on nature!

There are many reasons to eat clean meat: It requires much less water to produce and will cause far less climate change than conventionallyproduced meat; it doesn't require animals to suffer or die; it can feed far more people from the same amount of land; and it has the same or better nutritional content as conventionally-produced meat.

In sum, clean meat has many benefits for human health, animals, and the environment. But best of all, it's delicious real meat!

\footnotetext{
10 In order to hold constant features of the messages other than the content, these messages were kept as similar as possible in length and reading level. They were also informally pretested on a small convenience sample to confirm that they related narrowly to the intended message.
} 
Table A-2. Scale Measures

\section{Manipulation Checks}

1. Clean meat is unnatural.

2. Conventionally-produced meat is unnatural.

3. It is important for meat to be natural.

\section{Response Options}

Strongly disagree (1) to

Strongly agree (5)

\section{Response Options}

\section{Behavioral Intentions}

1. Would you be willing to try clean meat?

2. Would you be willing to buy clean meat regularly?

3. Would you be willing to eat clean meat as a replacement for conventionally-produced meat? ${ }^{1}$

4. How willing would you be to eat clean meat compared to plantbased substitutes (e.g., soy)?

\section{Attitudes}

1. For me to eat clean meat would be... ${ }^{2}$

2. For me to eat clean meat would be...

\section{Cognitive Beliefs}

Definitely no (1) to

Definitely yes (5)

1. To what extent do you think that eating clean meat is likely to be healthy?

2. To what extent do you think that clean meat is likely to be safe for human consumption?

3. To what extent do you think that clean meat is more environmentally friendly than conventionally-produced meat?

Much less (1) to

Much more (5)

\section{Response Options}

Extremely good (1) to

Extremely bad (7)

Extremely unpleasant (1) to

Extremely pleasant (7)

\section{Response Options}

4. To what extent do you think that clean meat is likely to look, taste, smell, and feel the same as conventionally-produced meat?

5. To what extent do you think that clean meat will have benefits for society?

Strongly disagree (1) to Strongly agree (5) 
Table A-2, Continued

Affect ("Indicate the extent to which each of the following describes Response Options your feelings about eating clean meat")

\begin{tabular}{|c|c|}
\hline 1. Disgusted ${ }^{2}$ & \multirow{6}{*}{$\begin{array}{l}\text { Not at all (1) to } \\
\text { Extremely (5) }\end{array}$} \\
\hline 2. Excited & \\
\hline 3. Anxious ${ }^{2}$ & \\
\hline 4. Comfortable & \\
\hline 5. Ethical & \\
\hline 6. Immoral $\left.\right|^{2}$ & \\
\hline
\end{tabular}


Table A-3. WTP Measure

\section{Page 1 (Introduction)}

Imagine that it is a few years in the future. Clean meat has been tested and approved for sale in the US. You are at your usual supermarket buying groceries. You will now be presented with several product choices. Please be as honest and accurate as possible in your responses.

\section{Page 2 (WTP for Chicken)}

You are looking at frozen chicken nuggets, and there are two options: conventionally-produced meat or clean meat.

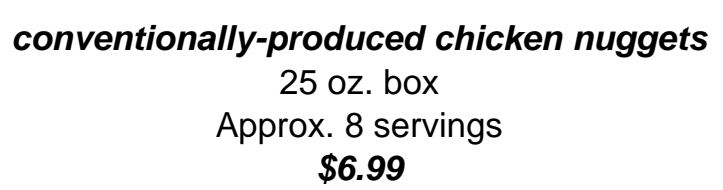

The conventionally-produced chicken nuggets cost $\$ 6.99$, as shown above. What is the most you would be willing to pay for the clean chicken nuggets? Please enter it in the box below.

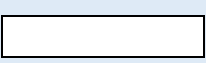

\section{OR}

If you would not buy the clean chicken nuggets at any price, please select this statement (click on it to highlight) instead of entering a value above.

\section{Page 3 (presented if box is checked instead of entering a value)}

You have indicated that you would not buy the clean chicken nuggets at any price. Would you buy the conventionally-produced chicken nuggets for $\$ 6.99$ instead?
$\square$ Yes
$\square$ No

Note. There were three measures of WTP for clean versus conventional meat. This table shows the WTP for chicken nuggets. The other two measures described beef burgers (with a value of $\$ 9.99$ for the conventional meat) and fish sticks (with a value of $\$ 5.99$ for the conventional meat). 


\section{Appendix B: Analysis Details}

Statistical analyses were performed using IBM SPSS Statistics, Version 22.

Per the pre-registered analysis plan, multivariate outliers were detected and reeled in to avoid extreme values exerting undue influence on subsequent analyses using methods discussed by Judd, McClelland, and Ryan (2017). This resulted in outlier values in outcome variables being adjusted to the nearest acceptable value for between 41 and 106 records per variable. The pattern of results did not differ substantially if outliers were left unadjusted.

For the main analyses, ANOVAs were used to compare measures of behavioral intentions, cognitive beliefs, attitudes, and affective responses between experimental conditions.

For willingness to try clean meat, which was considered a primary analysis in the pre-registration, planned pairwise comparisons were conducted between the control condition and each experimental condition. The other three pairwise analyses for willingness to try clean meat were Bonferroni-corrected.

All pairwise comparisons for the other Likert-type measures, which were considered secondary analyses, were corrected for post hoc analysis using Tukey's HSD, which is designed for making all possible comparisons.

Finally, ordinal regression was used to compare WTP for clean meat between experimental conditions. This was also considered a primary analysis, so as with willingness to try clean meat, planned pairwise comparisons were conducted between the control condition and each experimental condition. The other three pairwise analyses for WTP were Bonferroni-corrected. 


\section{Appendix C: Pairwise Comparisons}

Table C-1, on the next page, shows the results of all pairwise comparisons for the self-report measures.

Statistically significant differences between pairs of means are indicated using subscript letters. Means that differ significantly have different subscripts, whereas means that do not differ share a subscript. For example, in the 'perceived importance of naturalness' row, those in the 'clean meat is natural' condition showed significantly higher agreement than those in the 'challenging appeal to nature' condition (as indicated by subscripts $a$ and b, which these two conditions do not share). However, those in the 'conventional meat is unnatural' condition and the control condition were not significantly different from the other conditions (as indicated by subscripts a and $\mathrm{b}$, which are shared with all other conditions). As shown, most outcome variables did not differ significantly between conditions, though there were some significant differences in attitude and cognitive beliefs. 


\section{V faunalytics}

Table C-1. Outcome Variables in Each Experimental Condition and Overall

Condition Means

\begin{tabular}{|c|c|c|c|c|c|}
\hline Measure & $\begin{array}{l}\text { Overall } \\
\text { mean }\end{array}$ & $\begin{array}{l}\text { Clean meat } \\
\text { is natural }\end{array}$ & $\begin{array}{r}\text { Conventional } \\
\text { meat is } \\
\text { unnatural }\end{array}$ & $\begin{array}{r}\text { Challenging } \\
\text { appeal to } \\
\text { nature }\end{array}$ & Control \\
\hline \multicolumn{6}{|l|}{ Manipulation checks (5-point scale) } \\
\hline Perceived unnaturalness of clean meat & 2.98 & $3.01_{a}$ & $2.91 \mathrm{a}$ & $3.03 a$ & $2.99 a$ \\
\hline Perceived unnaturalness of conventional meat & 2.58 & $2.55 a$ & $2.82 b$ & $2.48 a$ & $2.48 a$ \\
\hline Perceived importance of naturalness & 3.80 & $3.94 a$ & $3.82 \mathrm{ab}$ & $3.69_{b}$ & $3.77_{\mathrm{ab}}$ \\
\hline \multicolumn{6}{|l|}{ Behavioral intentions (5-point scale) } \\
\hline Willingness to try clean meat & 3.88 & $3.81_{a}$ & $3.98 a$ & $3.81_{a}$ & $3.91 \mathrm{a}$ \\
\hline Willingness to buy clean meat regularly & 3.47 & $3.45 a$ & $3.57 \mathrm{a}$ & $3.38 a$ & $3.49 a$ \\
\hline $\begin{array}{l}\text { Willingness to eat clean meat as a replacement for } \\
\text { conventional meat }\end{array}$ & 3.54 & $3.48 \mathrm{a}$ & $3.65 a$ & $3.45 a$ & $3.57 \mathrm{a}$ \\
\hline $\begin{array}{l}\text { Willingness to eat clean meat compared to plant-based } \\
\text { substitutes (current consumers, } n=381 \text { ) }\end{array}$ & 3.67 & $3.66 a$ & $3.77 \mathrm{a}$ & $3.48 a$ & $3.74 a$ \\
\hline $\begin{array}{l}\text { Willingness to eat clean meat compared to plant-based } \\
\text { substitutes (non-consumers, } n=804 \text { ) }\end{array}$ & 3.81 & $3.76 a$ & $3.91 \mathrm{a}$ & $3.77 \mathrm{a}$ & $3.79 a$ \\
\hline \multicolumn{6}{|l|}{ Cognitive beliefs (5-point scale) } \\
\hline Perceived healthiness of clean meat & 3.64 & $3.61 \mathrm{ab}$ & $3.78 a$ & $3.53 b$ & $3.65 \mathrm{ab}$ \\
\hline Perceived safety of clean meat & 3.71 & $3.68 a b$ & $3.83 a$ & $3.63_{b}$ & $3.73 \mathrm{ab}$ \\
\hline Perceived environmental friendliness of clean meat & 4.03 & $4.04 \mathrm{ab}$ & $4.09 a$ & $3.87 b$ & $4.10_{a}$ \\
\hline $\begin{array}{l}\text { Perceived similarity in taste of clean meat to } \\
\text { conventional meat }\end{array}$ & 3.57 & $3.58 \mathrm{ab}$ & $3.65 a$ & $3.46 b$ & $3.60_{a b}$ \\
\hline Perceived benefits to society of clean meat & 3.79 & $3.75 \mathrm{a}$ & $3.82 \mathrm{a}$ & $3.71_{a}$ & $3.87 \mathrm{a}$ \\
\hline \multicolumn{6}{|l|}{ Attitude \& Affect } \\
\hline (Positive) attitude (7-point scale) & 4.88 & $4.78 a b$ & $5.07 c$ & $4.70_{a}$ & $4.98 \mathrm{bc}$ \\
\hline (Positive) affect (5-point scale) & 3.47 & $3.41_{a}$ & $3.55 a$ & $3.42 \mathrm{a}$ & $3.49_{a}$ \\
\hline
\end{tabular}

